\title{
O comércio peruano em Benjamin Constant no Amazonas, Brasil
}

\section{The Peruvian trade in Benjamin Constant in Amazonas, Brazil}

Alex Sandro Nascimento Souza - Mestre em Geografia pela Universidade Federal do Amazonas. Manaus-AM. E-mail: alexgeobc@hotmail.com

José Aldemir Oliveira - Professor Titular da UFAM; pesquisador do CNPq; docente do curso de Mestrado em Geografia Universidade Federal do Amazonas. Manaus-AM. E-mail: jaldemir2013@uol.com

\section{Resumo}

O objetivo deste artigo é a análise das dinâmicas do comércio desenvolvido pelos imigrantes peruanos na cidade de Benjamin Constant, localizada no oeste do estado do Amazonas, precisamente na tríplice fronteira (Brasil, Peru e Colômbia), com um mercado composto por imigrantes de origem rural e urbana, que ganham a vida como comerciantes formais (hotelaria, restaurante, salão de beleza, autopeças, mercadinhos, lojas de vestuário), comerciantes informais (pequenas tabernas de eletrônicos importados, bijuterias, brinquedos), e comerciantes subinformais (vendedores ambulantes, e comunidades agrícolas israelitas). A cidade está inserida numa área relativizada ao "estigma da fronteira", do ilegal social econômico do tráfico de drogas, mas não é só isso, pois é possível identificar práticas espaciais locais que transcendem essas imagens e evidenciam modos de vidas diferenciados, visíveis no hibridismo dos idiomas, da culinária, da música, da religião, do lazer, da cultura de uma vida ribeirinha amazônica que se contextualiza na cidade da fronteira.

\section{Palavras-chave}

Comércio peruano. Cidade de fronteira. Cidade amazônica.

\begin{abstract}
The analysis of the dynamics of trade developed by Peruvian immigrants in the city of Benjamin Constant located in the west of Amazonas state precisely in the triple frontier (Brazil, Peru and Colombia) with a market composed of immigrants from rural and urban origin who make their living as traders formal (hotel, restaurant, salon, auto, grocery stores, clothing stores), informal traders (small electronics imported taverns, jewelry, toys), and subinformais traders (hawkers, and Israeli farming communities), is the objective of this article. The city is set in a relativized area to "the border stigma" of economic social illegal drug trafficking, but not only that, it is possible to identify local spatial practices that transcend these images, which show different ways of life, visible hybridity of language, cuisine, music, religion, leisure, culture of an Amazonian river life that is contextualized in the border town.
\end{abstract}

\section{Keywords}

Peruvian trade. Border city. Amazonian city. 


\section{INTRODUÇÃO}

Estudar as cidades amazônicas nos remete a lugares que carregam especificidades de diferentes escalas. São cidades que vão além de um limite geográfico, da soberania restrita ou relativa a um país, e atendem interesses geopolíticos nacionais, ao mesmo tempo em que são locais que articulam a sua hinterlândia, por onde circulam as populações indígenas e caboclas. A Amazônia saiu de uma fase de esquecimento e entrou numa fase em que todos falam dela, dão opinião sobre ela, mas preferencialmente à distância. Do romantismo sobre as belezas naturais que devem ser contempladas de modo idílico ao utilitarismo verde, todos querem protegê-la ou se apossar de suas riquezas. Parece que todos olham e falam da Amazônia sem vivenciá-la.

Esse artigo não se coloca nem num extremo nem noutro. Parte-se da vivência na Amazônia para estudar Benjamin Constant, uma cidade localizada no sudoeste do Amazonas, na região do Alto Solimões, distando 1.118,60 km em linha reta de Manaus, sendo o $6^{\circ}$ município mais distante da capital (Figura 1). Em âmbito nacional, o acesso à cidade Benjamin Constant ocorre de duas maneiras, sendo a mais usual realizada por via fluvial, com aproximadamente cinco a oito dias em viagens de barco de Manaus até a referida cidade (dependendo da sazonalidade do rio Solimões); já a outra é o acesso através do transporte aéreo (Trecho Manaus-Tabatinga), que se completa por meio fluvial em embarcações locais, lanchas rápidas (Trecho Tabatinga-Benjamin Constant). Salienta-se que uma passagem aérea no trecho Manaus-Tabatinga pode custar entre $\mathbf{R} \$ 400,00$ (quatrocentos reais) a $\mathrm{R} \$ 1.000,00$ (um mil reais), dependendo da temporada e da antecedência com que é adquirida.

O município de Benjamin Constant tem uma população estimada de 38.533 habitantes (IBGE, 2010), tendo como peculiaridade de localização, relações fronteiriças com os territórios do Peru e Colômbia. Nesse contexto, desenvolvem-se atividades predominantemente relacionadas ao comércio e serviços, em sua maioria executadas por imigrantes de origem peruana. Esta é a questão abordada neste artigo, a partir das dinâmicas econômicas das cidades amazônicas. 
Figura 1 - Localização do município Benjamin Constant.

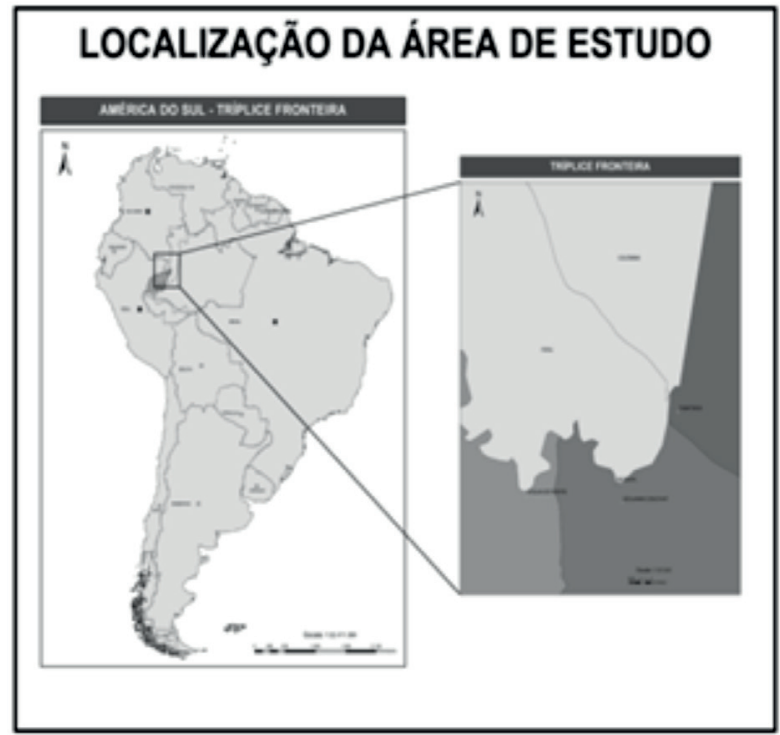

Fonte: SEPLAN, 2014. Organização: Souza, 2014.

\section{OS CIRCUITOS COMERCIAIS, O LUGAR E O MUNDO}

Em sua análise do espaço, Milton Santos (2004) sugere que a economia urbana dos países em desenvolvimento divide-se em dois setores, um circuito superior e um circuito inferior. Embora a teoria dos circuitos da economia ainda careça de aplicação em lugares como a Amazônia, inserimos inicialmente o estudo a partir dessa concepção, com ênfase no circuito inferior ou setor terciário, representado pelo comércio. Nesse sentido, para melhor compreensão dessa questão, caracterizamos e tipificamos o comércio realizado pelos peruanos em Benjamin Constant como subinformais, informais e formais, deixando claro, desde o início, que essas práticas não são estanques, ao contrário, complementamse, misturam-se e, em alguns casos, fica difícil estabelecer o limite de cada um.

Entretanto, buscando uma aproximação com a realidade que se verifica na cidade de Benjamin Constant, traremos as proposições de Roberto Lobato Corrêa (1989), que insere na discussão a análise a partir do contexto de redes urbanas hierarquizadas, no qual cidades com maior dinâmica econômica mantêm relações e influenciam as dinâmicas de cidades de menor expressão econômica. Salientase a citação de Schor e Oliveira (2011), que compreendem Benjamin Constant como uma cidade com dinâmicas peculiares, de responsabilidade territorial que mantém relações e influências econômicas, políticas e culturais numa rede 
urbana que extrapola o âmbito local para se inserir na dimensão regional, com influência na região do Alto Solimões e, pela sua posição estratégica, estabelece relações com outras cidades da fronteira. Partindo desse princípio, detalha-se, a seguir, a dinâmica desses circuitos comerciais que se materializam num âmbito do comércio realizado por peruanos em Benjamin Constant, o que implica numa rede urbana amazônica a partir da dinâmica de fronteira.

Trata-se primeiramente do comércio que se tipifica como formal, ou seja, aquele em que os comerciantes peruanos já se fixaram na cidade há muito tempo, os quais possuem documentação legalizada, nacionalidade e estabelecimentos comerciais com alvará de funcionamento expedido pela Prefeitura Municipal. Nesse segmento, verificaram-se as características funcionais sugeridas por Milton Santos, visto que no circuito superior ocorre a aquisição direta de mercadorias de grandes empresas, fábricas ou distribuidoras inseridas na economia nacional, na maioria das vezes multinacionais, passando para uma empresa de transportes intermediária, que repassa a mercadoria ao circuito inferior, ou seja, ao pequeno comércio. Verificou-se que nesse segmento as mercadorias comercializadas em Benjamin Constant são, em suma, de origem brasileira, oriundas do polo industrial de Manaus ou de indústrias localizadas em outros estados brasileiros, como exemplo, os comerciantes peruanos que trabalham especificamente com peças de motocicletas e automóveis, que adquirem as mercadorias em Manaus, Mato Grosso e Paraná (Figura 2).

Figura 2 - Vitrine de loja de motopeças.

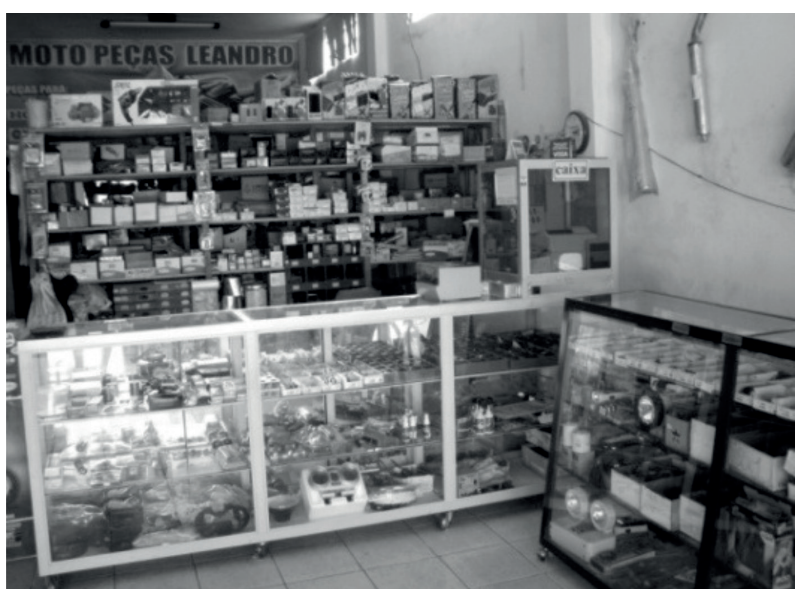

Fonte: Souza, pesquisa de campo, julho 2012.

Observou-se um fato curioso ao entrevistar um dos proprietários descendente de peruanos que trabalha nesse segmento, que demonstrou a 
preocupação com outros comerciantes peruanos e brasileiros que comercializam peças de motocicletas similares oriundas do Peru: “[...] Assim fica difícil trabalhamos com produtos nacionais; pagamos impostos, enquanto peruanos e também brasileiros vendem peças oriundas do Peru, de baixa qualidade, porém com o preço bem abaixo da média."

Em outra escala geográfica estão os empresários ditos peruanos, que trabalham com o segmento das confecções, vestuário, cama, mesa e banho. Estes apresentam uma rede de contatos ampla e diversificada, como pode ser observado no mapa a seguir (Figura 3).

Figura 3 - Mapa dos polos nacionais fornecedores de mercadorias para Benjamin Constant.

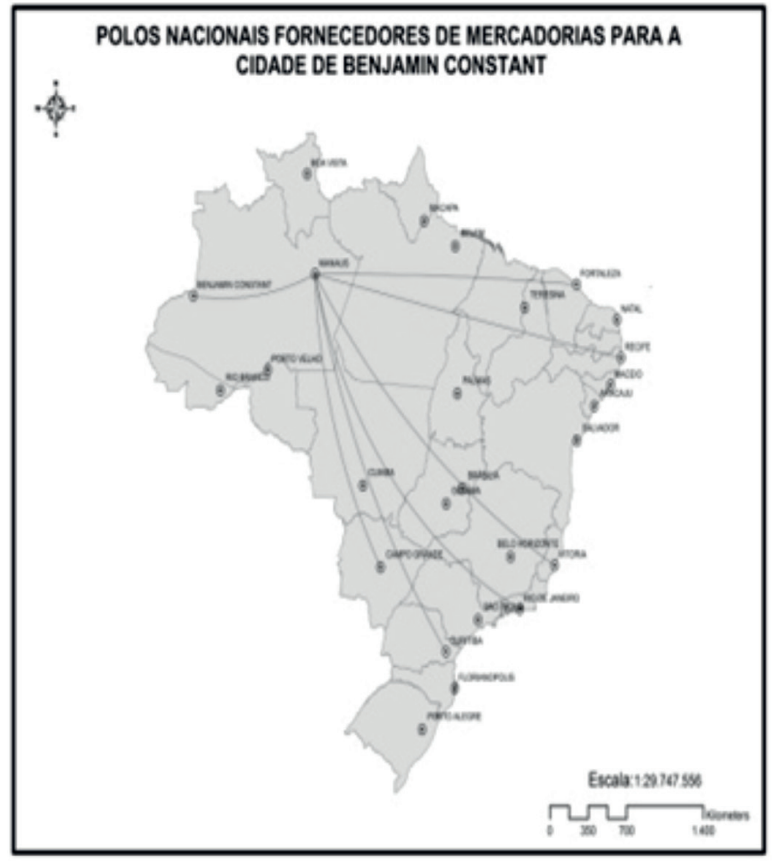

Fonte: Souza, 2014.

Como se observa, a rede de relações se amplia e, de forma sintetizada, pode-se sustentar que as mercadorias são adquiridas nesses centros comerciais correspondentes às cinco regiões brasileiras (Norte, Nordeste, Sudeste, Sul e Centro-Oeste), a partir de contratos com empresas de transporte que ligam as demais regiões e fazem escala em Manaus, com destino final em Benjamin Constant, mesclando o transporte aéreo e fluvial. Exemplos disso são as confecções, em geral adquiridas em Fortaleza; Jeans e calçados em São Paulo; vestuário infantil em Pernambuco; vestuário adulto variado em Goiânia; calçados e vestuário em Nova 
Serrana (Minas Gerais), conhecida como a capital mineira do calçado esportivo; e redes de dormir em São Bento (Paraíba), conhecida como a terra da rede, por produzir mais de 12 milhões de redes por ano. A Tabela 1, elaborada a partir dos dados obtidos nos formulários de entrevistas aplicados aos comerciantes peruanos, denota os principais fluxos de mercadorias em âmbito nacional.

Tabela 1 - Principais produtos nacionais comercializados nos estabelecimentos peruanos em Benjamin Constant, no período de 2012-2013.

\begin{tabular}{|l|l|c|c|}
\hline Produto & \multicolumn{1}{|c|}{ Origem } & $\begin{array}{c}\text { Forma de } \\
\text { obtenção }\end{array}$ & $\begin{array}{c}\text { Forma de } \\
\text { transporte }\end{array}$ \\
\hline $\begin{array}{l}\text { Bermudas, calças, camisas, } \\
\text { lingeries, redes de dormir }\end{array}$ & Fortaleza & $\begin{array}{l}\text { Fornecedor e } \\
\text { Pessoalmente }\end{array}$ & $\begin{array}{c}\text { Empresa } \\
\text { transportadora }\end{array}$ \\
\hline Jeans e calçados & São Paulo & $\begin{array}{l}\text { Fornecedor e } \\
\text { Pessoalmente }\end{array}$ & $\begin{array}{c}\text { Empresa } \\
\text { transportadora }\end{array}$ \\
\hline Vestuário infantil & Goiânia & $\begin{array}{l}\text { Fornecedor e } \\
\text { Pessoalmente } \\
\text { Pessoalmente }\end{array}$ & $\begin{array}{c}\text { Empresa } \\
\text { transportadora }\end{array}$ \\
\hline Vestuário adulto variado & Nova Serrana & $\begin{array}{l}\text { Fornecedor e } \\
\text { Pessoalmente }\end{array}$ & $\begin{array}{c}\text { Empresa } \\
\text { transportadora }\end{array}$ \\
\hline Calçado e vestuário em geral & $\begin{array}{l}\text { Fornecedor e } \\
\text { Pessoalmente }\end{array}$ & $\begin{array}{c}\text { Empresa } \\
\text { transportadora }\end{array}$ \\
\hline Redes de dormir e produtos têxteis & São Bento & \multicolumn{2}{|c}{} \\
\hline
\end{tabular}

Fonte: Souza, pesquisa de campo, 2012-2013.

De acordo com as entrevistas, os polos comerciais são os identificados na Figura 3 e na Tabela 1, porém as mercadorias são adquiridas conforme da variação de preços, ou seja, analisam-se os produtos que são oferecidos simultaneamente nesses centros e, dependendo dos preços são adquiridos pelo menor valor. Outro fator é a relação de aquisição. Segundo os entrevistados não há dependência de único fornecedor, as aquisições são mescladas com fornecedores relativamente fixos, e também a compra de cunho pessoal por contato familiar, com base em pesquisa prévia periódica entre os centros citados. Todavia, para a realização do transporte das mercadorias, atualmente contrata-se uma empresa especializada na modalidade rodo-fluvial - a Transportadora Bertoline, que, de acordo com os comerciantes, entrega as mercadorias no prazo de 30 dias, em perfeito estado de conservação, na porta do estabelecimento, um luxo para as condições precárias de transporte na Amazônia.

O que se conclui das informações coletadas junto a esse segmento, caracterizado como comerciantes formais, é que os administradores partem de um contexto familiar, ou seja, os parentes - irmão, irmã, primo ou filhos - que administram o estabelecimento, enquanto os mais antigos no ramo preocupam- 
se em manter novos contatos com lugares que possam oferecer melhores mercadorias a preços acessíveis.

No âmbito dos comerciantes informais, ou seja, aqueles que não possuem documentação permanente de nacionalidade brasileira, mas os estabelecimentos funcionam a partir de alvarás de licenciamento expedidos pela prefeitura local, como forma de arrecadação de taxas, além de outros documentos fornecidos por órgãos competentes, como a Secretaria da Fazenda (SEFAZ). Esses comerciantes inserem-se numa rede de relações que extrapolam o contexto nacional, com fluxos de mercadorias que delineiam o limiar da (i)legalidade. A característica principal nesse segmento é a grande variedade na oferta de mercadoriaa, conforme se observa an Figura 4.

Figura 4 - Variedades de mercadorias no comércio peruano e documentação de funcionamento.

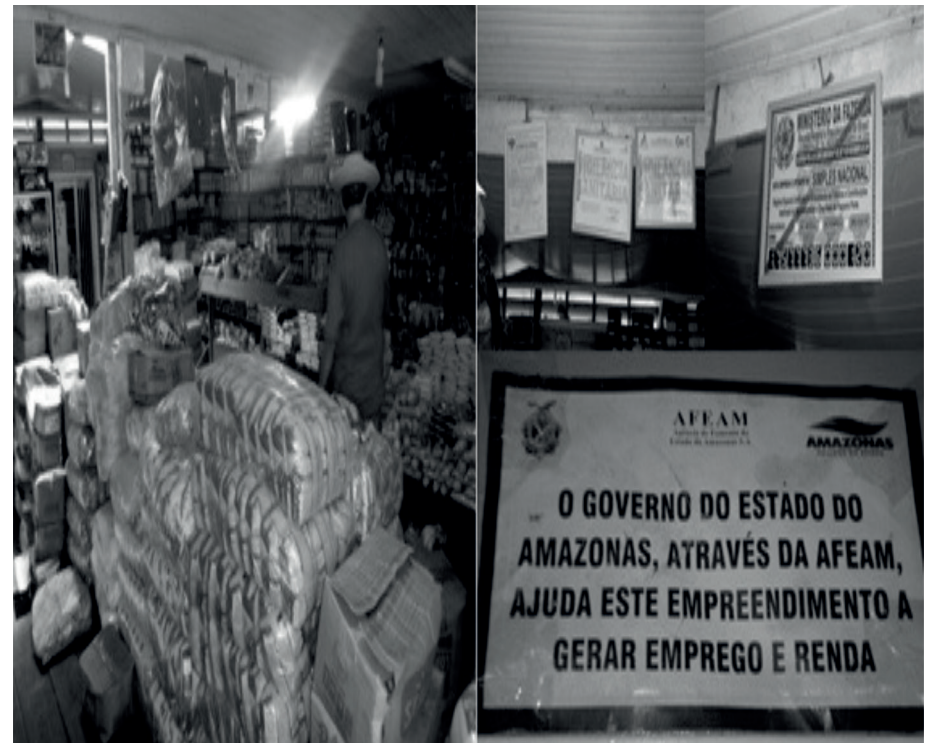

Fonte: Souza, pesquisa de campo, setembro de 2013.

A partir dos estudos sobre as trajetórias de pesquisa em Antropologia Urbana, realizados pelo professor José Guilherme Cantor Magnani (2012), no livro Da periferia ao centro: trajetórias de pesquisa em Antropologia Urbana busca-se a aproximação da realidade e do cotidiano desse comércio, denotando as falas dos sujeitos, tanto de comerciantes peruanos quanto de brasileiros e da população em geral. Neste sentido, é muito comum a afirmação na cidade de que esses empresários comercializam produtos ilegais, relativos ao narcotráfico. Nas entrevistas verificam-se opiniões, em tom sutil: “[...] é estranho - eles aparecem 
ficam aí e de repente já estão comprando as coisas, casas, construindo [...]"; entretanto, outros são mais incisivos "[...] esses paisanos são todos traficantes - é impossível mudança assim tão rápida, em poucos meses eles já estão construindo prédios, comprando motocicletas ou motocarros - de onde vem esse dinheiro?" E se o diálogo for mais alongado em grupo, em tom amistoso, por exemplo, na feira pela manhã, onde se sabe das notícias da cidade, com certeza vai aparecer sempre alguém que sabe de outra pessoa que conhece as transações de algum comerciante peruano com um traficante de Benjamin Constant - ou um conhecido afirmando que conhece ou que viu fulano transportando ou se comportando de forma suspeita, e que logo em seguida comprou imóvel, automóveis, motos ou terrenos na cidade. Aliás, qualquer pessoa da cidade na fronteira que tiver ascensão econômica e apresentar e ou começar a construir algum imóvel, adquirir veículos (motocicleta, automóvel) ou viajar mais de uma vez para capital do estado no período de um ano será considerado traficante ou envolvido com o narcotráfico. Todos esses atributos se agravam se o indivíduo for peruano. Como afirma Sidney Silva (2012, p. 268), "tais acusações, acabam por estigmatizá-los e transformá-los no 'bode expiatório’ dos problemas do lugar e, ao mesmo tempo, como categorias diferenciadoras nas relações identitárias locais."

O que impressiona os moradores locais é a imagem dos comerciantes peruanos que ascendem economicamente e, neste sentido, é evidente nos relatos da maioria dos benjaminenses o tom xenofóbico e estigmatizado em relação à figura do imigrante peruano, como, por exemplo, "paisano ladrão, traficante" ou, em outra dimensão, "peruano tchola" similar ao termo homossexual, dentre outras expressões pejorativas em tom de vulgaridade.

$\mathrm{O}$ que se constatou na pesquisa foi que a característica principal entre os imigrantes peruanos envolvidos na atividade de comércio é o trabalho intenso e a dedicação ao seu negócio, sem diferenciação entre patrão ou empregado, mesmo porque, em geral, utilizam mão de obra familiar. Todavia, no âmbito das estratégias econômicas, a característica principal é a variedade das mercadorias industrializadas ofertadas nesses estabelecimentos, como congelados (frango, salsicha), arroz, açúcar, bebidas, quase sempre de origem brasileira (Figura 5).

É ofertada uma grande variedade de frutas, legumes e verduras, alguns importados da Argentina, Chile e Peru, e outros produzidos no local. Há também uma variedade de bebidas, de origens diversas, como do Peru (Inca-cola, cerveja Cusqueña), da Colômbia (cerveja Águila), equipamentos eletrônicos e bijuterias importados de países asiáticos. Outro aspecto relevante são os preços das mercadorias. O lema do comerciante peruano é vender barato para vender mais. Observe a Tabela 2, que denota a variedade de produtos e suas respectivas origens. 
Figura 5 - Mercadorias no porto de Benjamin Constant, oriundas de Manaus.

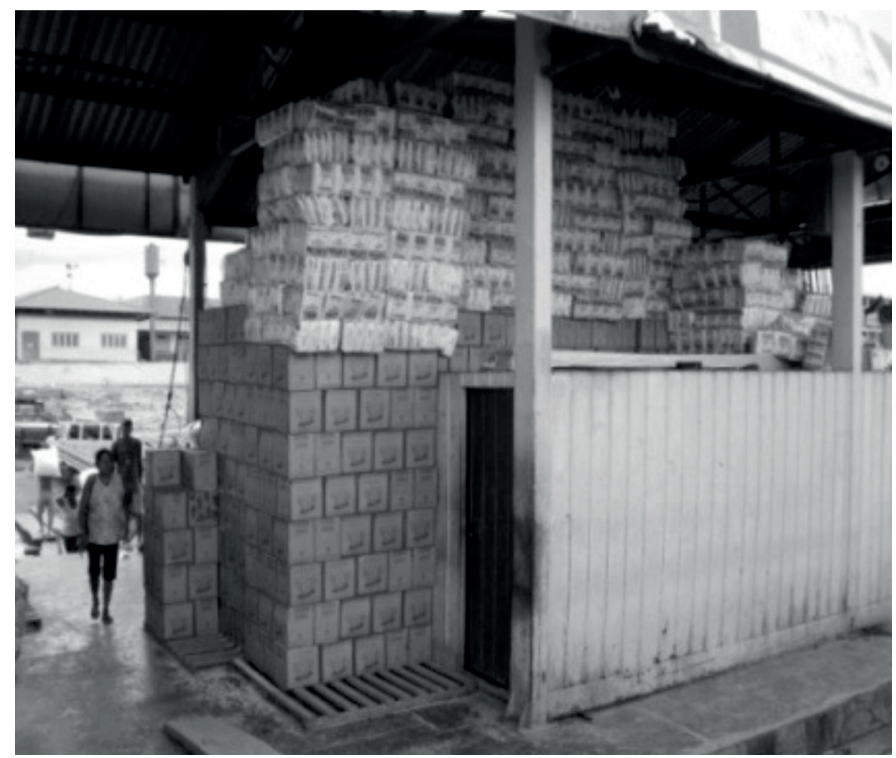

Fonte: Souza, pesquisa de campo, junho de 2012.

Tabela 2 - Principais produtos comercializados em Benjamin Constant (20122013).

\begin{tabular}{|c|c|c|c|c|c|c|c|}
\hline $\begin{array}{c}\text { Mercadorias/ } \\
\text { Produtos }\end{array}$ & Brasil & Peru & Colômbia & Argentina & Chile & Holanda & Ásia \\
\hline $\begin{array}{l}\text { Congelados em } \\
\text { geral }\end{array}$ & $\mathrm{X}$ & & & & & & \\
\hline Arroz, açúcar & $\mathrm{X}$ & & & & & & \\
\hline Frutas & & $\mathrm{X}$ & & $\mathrm{X}$ & $\mathrm{X}$ & & \\
\hline Trigo & $\mathrm{X}$ & & & $\mathrm{X}$ & & & \\
\hline $\begin{array}{ll}\text { Materiais } & \text { de } \\
\text { construção, } & \\
\text { gasolina } & \end{array}$ & & $\mathrm{X}$ & & & & & \\
\hline Queijo enlatado & & & & & & $\mathrm{X}$ & \\
\hline Bebidas & $\mathrm{X}$ & $\mathrm{X}$ & $\mathrm{X}$ & & & & \\
\hline Frutos do mar & & $\mathrm{X}$ & & & & & \\
\hline $\begin{array}{l}\text { Eletroeletrônicos } \\
\text { em geral, } \\
\text { brinquedos }\end{array}$ & & $\mathrm{X}$ & $\mathrm{X}$ & & & & $\mathrm{X}$ \\
\hline
\end{tabular}

Fonte: Souza, pesquisa de campo, 2012/2013.

Como se pode observar, a origem das mercadorias revela a conexão entre circuitos comerciais - o superior e o inferior - ou seja, essa análise permite situar 
múltiplos espaços geográficos que se conectam, do âmbito local ao contexto mundial. Na Figura 6 observa-se uma variedade de frutas e verduras oriundas do Chile e da Argentina.

Figura 6 - Frutas e verduras oriundas do Chile e da Argentina ofertadas no comércio peruano em Benjamin Constant.

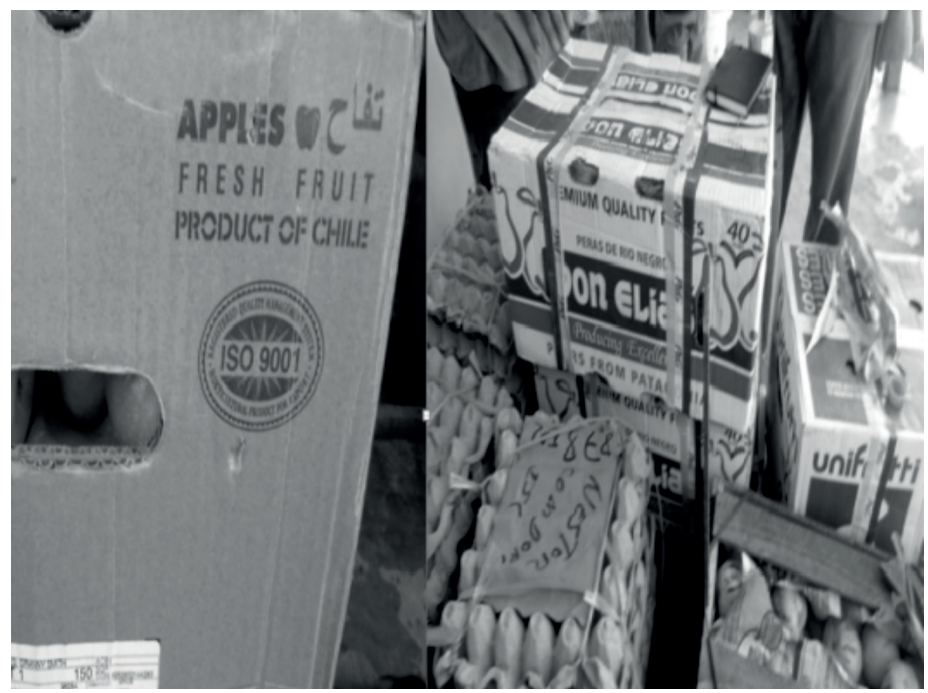

Fonte: Souza, pesquisa de campo, setembro de 2013.

Porém, essa característica não significa que estes comerciantes tenham conexão direta com esses polos multinacionais, mas estabelecem relações que se amplificam a partir de polos econômicos regionais que interligam o lugar ao mundo, conforme mostrado na Figura 7.

O mapa (Figura 7) demonstra a trajetória das frutas e dos frutos do mar comercializados pelos peruanos em Benjamin Constant. As frutas (peras, uvas, maçãs) são oriundas da Argentina e do Chile, e os frutos do mar (camarão, lula, caranguejo, mariscos) são oriundos da costa peruana do oceano Pacífico. Ambos chegam até Iquitos via aérea e fazem o percurso seguinte até Benjamim Constant por via fluvial.

Considerando-se os modos de entrada dessas mercadorias, os circuitos se afunilam e as redes de relações permitem maior compreensão desse segmento comercial. Prosseguindo com a análise, excluindo-se a origem, evidencia-se a forma de aquisição dos produtos, pode-se perceber que há uma rede comercial regional com dinâmicas e características peculiares que se estabelecem em Benjamin Constant. Observe o mapa das principais cidades onde são distribuídas as mercadorias regionalmente (Figura 8). 
Figura 7 - Mapa do circuito das frutas e dos frutos do mar.

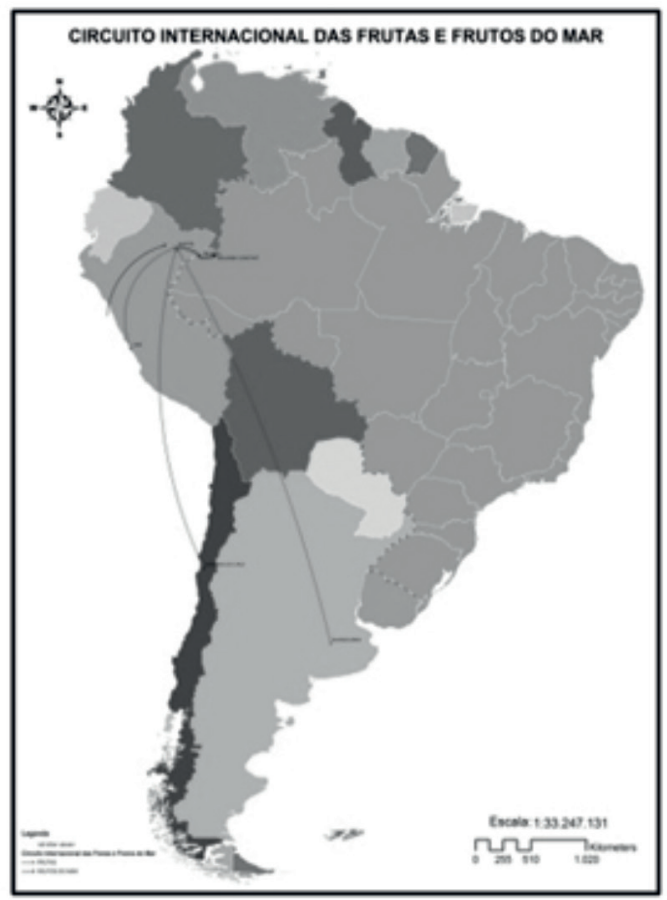

Fonte: Organizado por Souza, 2014.

Figura 8 - Mapa dos polos econômicos regionais.

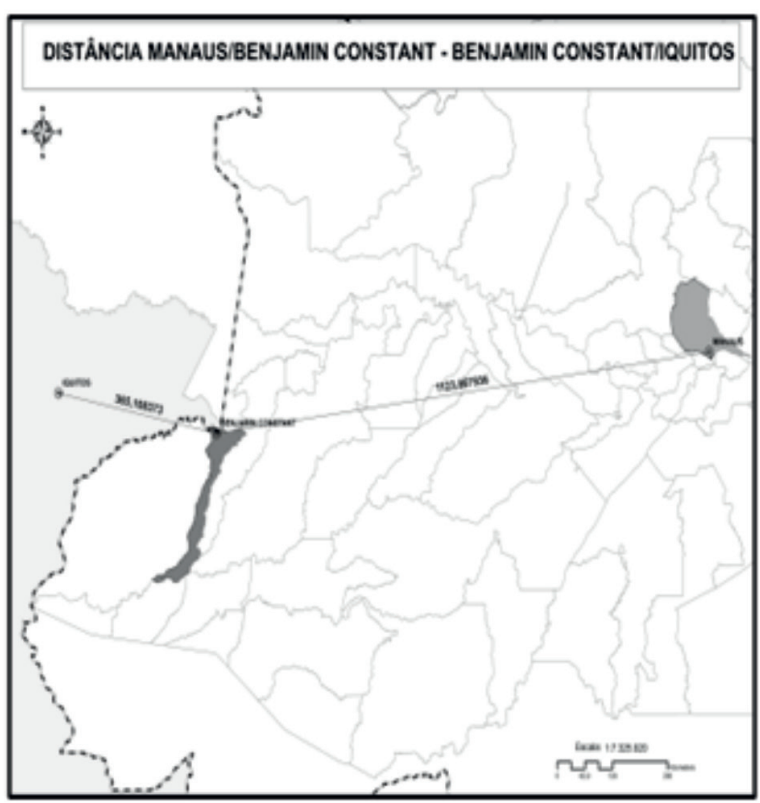

Fonte: SEPLAN, 2014. Organização: Souza, 2014. 
Como se observa no mapa (Figura 8), que indica os dois polos regionais de produção e distribuição de mercadorias - Manaus (Brasil) e Iquitos (Peru) sendo que a distância entre Manaus e Benjamin Constant é de aproximadamente $1.123 \mathrm{~km}$ em linha reta, e entre Iquitos e Benjamin Constant de aproximadamente $365 \mathrm{~km}$ em linha reta, o que significa um raio de influência significativo na configuração da rede urbana regional, que extrapola o território brasileiro.

Observa-se ainda neste mapa que a aquisição da maior parte das mercadorias de origem internacional ocorre por meio da distribuição oriunda de Iquitos no Peru, com entrada no Brasil via malha fluvial, porém as mercadorias não são desembarcadas diretamente em Benjamin Constant. A maioria das mercadorias de origem estrangeira é adquirida principalmente nas casas comerciais flutuantes que se localizam ao longo do rio Javari nas imediações de Islândia (Peru), as quais são abastecidas por grandes embarcações que fazem periodicamente o eixo fluvial Iquitos/Islândia. Nesse mesmo âmbito existe também uma parcela significativa de comerciantes que mantêm contatos com parentes ou fornecedores empresários que as adquirem em Iquitos e despacham para aquela cidade por meio das referidas embarcações (Figura 9).

Figura 9 - Entrada de mercadorias de origem peruana em Benjamin Constant.

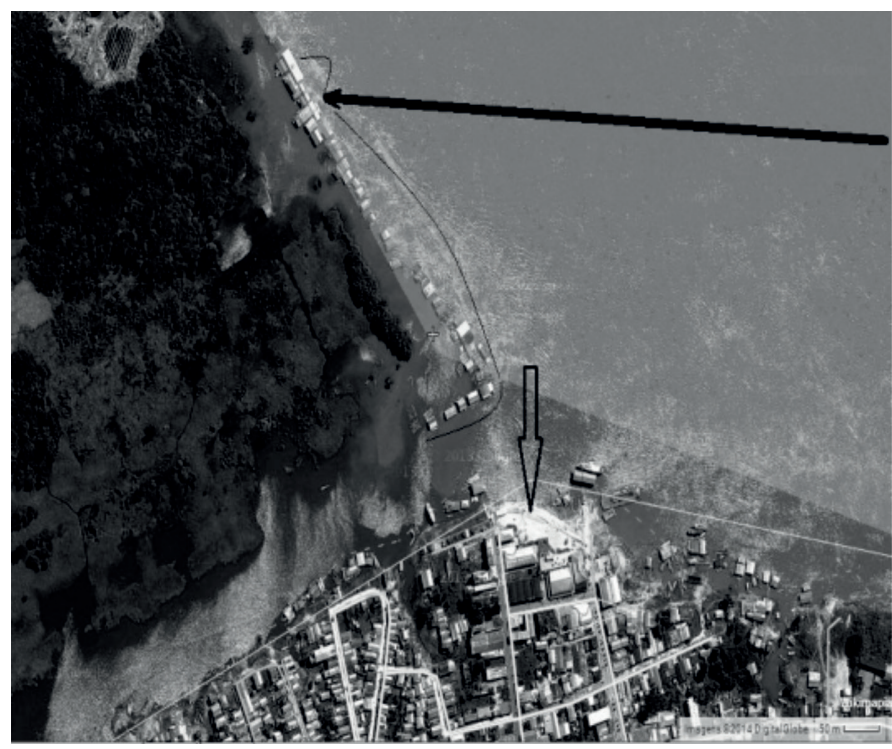

Fonte: Wikimapia, 2014. Organização: Souza, 2014.

Note-se na Figura 9 a seta na parte superior indicando o entreposto, as casas comerciais flutuantes situadas na cidade vizinha, Islândia (Peru), e a seta na parte inferior indica a cidade Benjamin Constant, destino final das mercadorias. 
Ressalta-se que esses comerciantes trabalham no limiar da (i)legalidade, pois é necessário ter cautela na forma como as mercadorias entram definitivamente em Benjamin Constant. Apesar da fiscalização não ser permanente, já houve muitos casos de apreensão de mercadorias, principalmente quando se trata de grandes volumes de cargas de materiais de construção, combustível, especialmente a gasolina. E quando isso ocorre, implica em grandes prejuízos, considerando as baixas condições econômicas desses comerciantes.

A estratégia dos comerciantes peruanos, brasileiros e da população em geral mantém um padrão cujas mercadorias são adquiridas nas casas comerciais flutuantes (Figura 10) e transportadas nos chamados "canoãos" ou "rabetas", de Islândia até Benjamin Constant (10 a 15 minutos de viagem), que atracam nas margens do rio e desembarcam os produtos rapidamente.

Figura 10 - Desembarque de mercadorias oriundas de Islândia em Benjamin Constant.

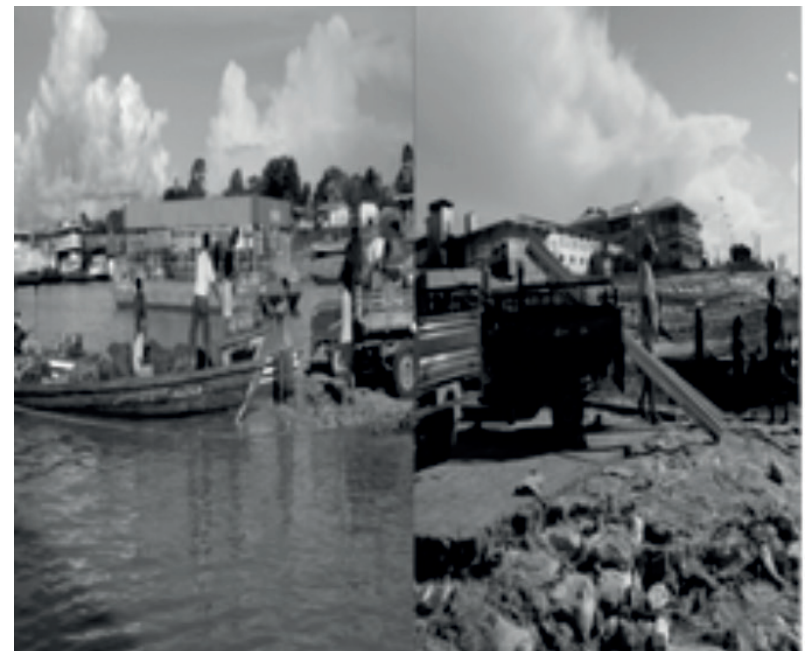

Fonte: Souza, pesquisa de campo, dezembro de 2012.

Simultaneamente, as mercadorias são desembarcadas e embarcadas nos denominados "motocarros" - motocicletas que possuem uma carroça acoplada na parte traseira. Esses veículos também são adquiridos nas casas flutuantes de Islândia por um preço acessível, de aproximadamente $\mathrm{R} \$$ 5.000,00 (cinco mil reais), inferior ao valor cobrado em Manaus, onde custavam, em média $\mathrm{R} \$$ 8.000,00 (oito mil reais) no período da pesquisa (2012-2013). Salienta-se que os motoristas desses veículos são moradores da própria cidade e fazem parte de uma associação organizada, composta por presidente, vice-presidente, tesoureiro e secretário. Esses trabalhadores adotam preços tabelados, mas com valores diferenciados para transportar mercadorias em área urbana, área rural e ou 
interurbana (de Benjamin Constant a Atalaia do Norte). Observe na Figura 11 a tabela de preços desse serviço.

Figura 11 - Transportadores de cargas em motocarros e tabela de preços do transporte em Benjamin Constant.

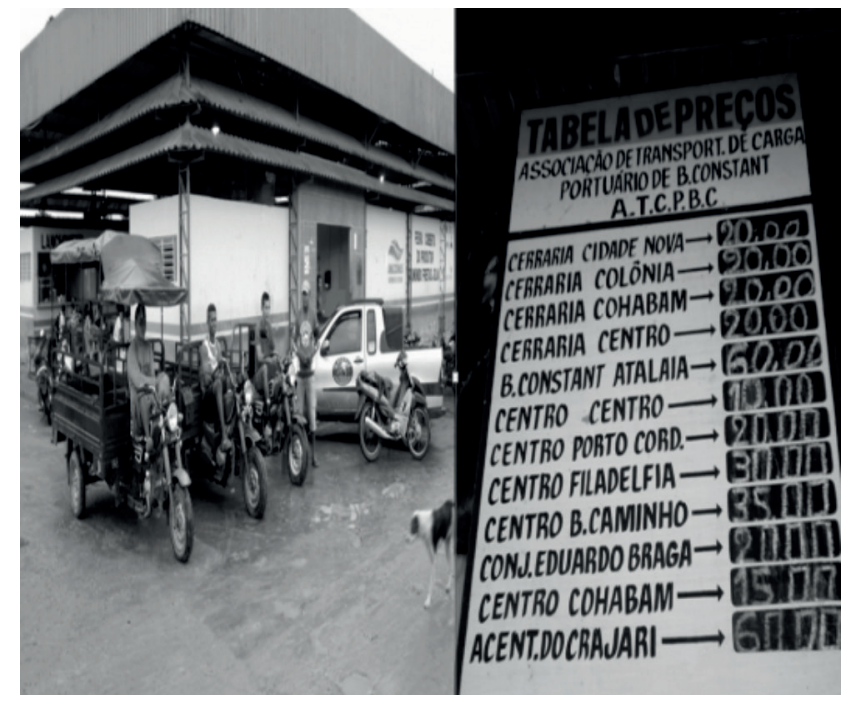

Fonte: Souza, pesquisa de campo, maio de 2013.

Entretanto, também existem comerciantes, sejam peruanos ou brasileiros, que possuem frota particular de transporte e, nesses casos, a dinâmica de desembarque e embarque é mais rápida e tensa, pois, além das mercadorias, os veículos também podem ser apreendidos.

Como se pode observar na Figura 12 há empresários que dispõem de frota de cinco ou mais veículos, absorvendo mão de obra local para pilotar e transportar cargas e passageiros. Outra dimensão refere-se ao serviço de fiscalização. Enquanto que localmente as autoridades reconhecem a importância desses serviços, há certa apreensão quanto à chegada da Polícia Federal. As relações são tensas e, no âmbito da pesquisa, isso foi constatado com questionamentos ao pesquisador sobre o motivo da sondagem e das fotografias. Como é normal nessas áreas de fronteira e com os diretamente envolvidos, paira no ar uma indignação acerca dos órgãos de controle, como pode ser analisado no caso transcrito a seguir, no qual um comerciante brasileiro descendente peruanos reclama da atitude de um órgão de fiscalização que atua na fronteira: "Eles chegam aqui sem avisar, tomam tudo, não querem saber se custou o suor do trabalho diário. Pra nós é difícil perder dois ou três veículos destes [...] é um prejuízo de aproximadamente $\mathrm{R} \$$ 15.000, 00 (quinze mil reais) [...] aonde se consegue isso de uma hora pra outra? 
Ninguém tá roubando, nem traficando - isso é trabalho duro [...]". Observa-se a fragilidade do discurso, porém, como assinalado por muitos autores, as relações são tensas; e as reclamações e as razões, sejam do lado institucional ou do lado dos comerciantes, mais do que divergências, refletem as contradições dos múltiplos interesses em conflito na fronteira.

Figura 12 - Frota de veículos de carga particular em Benjamin Constant.

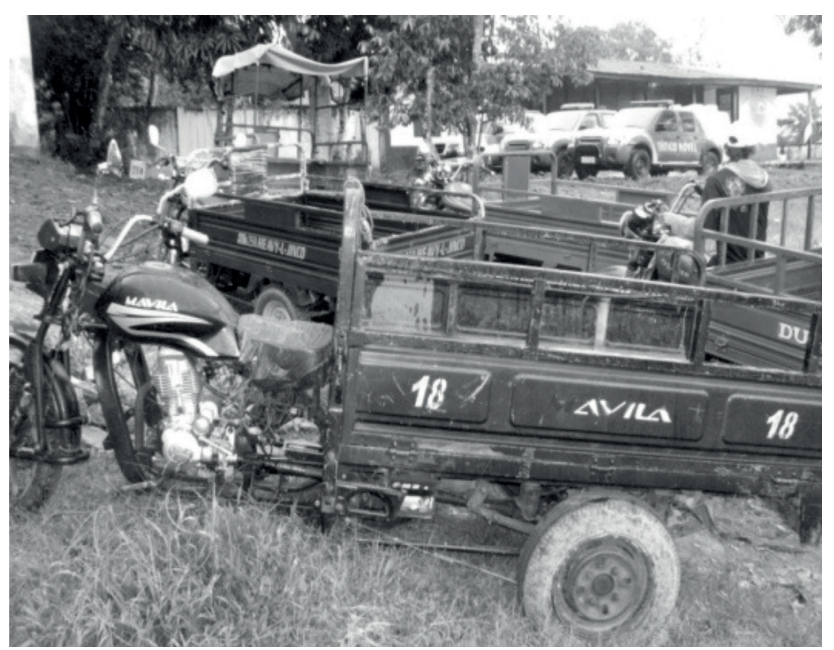

Fonte: Souza, pesquisa de campo, julho de 2012.

O movimento é mais intenso pela manhã, quando se observam catraias oriundas de Islândia chegando a todo o momento e motocarros transitando, descendo e subindo o pequeno declive que dá acesso às ruas de Benjamin Constant (Figura 13).

Figura 13 - Transporte de mercadorias na área portuária de Benjamin Constant.

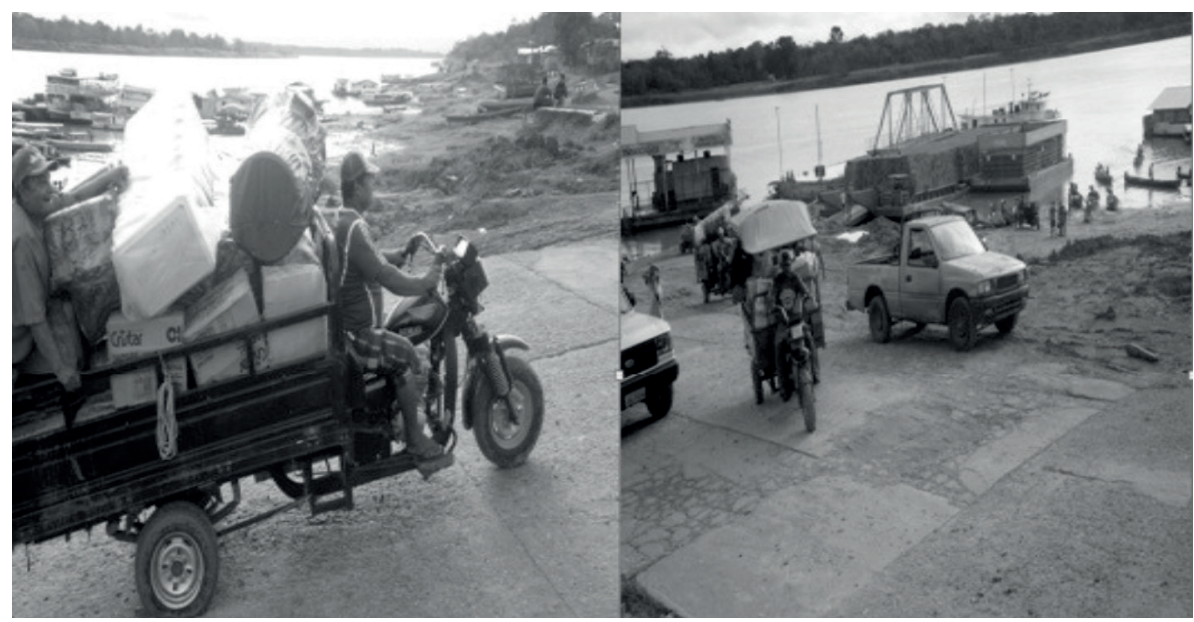

Fonte: Souza, pesquisa de campo, setembro de 2013. 
Chegam mercadorias variadas na área portuária de Benjamin Constant, como gasolina, materiais de construção, vasilhames, depósitos, motocicletas, alimentos em geral, frutas, verduras, animais, entre outras. Todavia, há outras vias de entrada dessas mercadorias na cidade, mas que se realizam somente no período de enchente, como, por exemplo, pelo rio Javari, que dá acesso às ruas da área oeste, mas esse trajeto geralmente é realizado pelos moradores locais. Também há uma entrada pelo igarapé denominado "Esperança", que dá acesso às ruas da área leste da cidade, onde há concentração e expansão do comércio realizado pelos peruanos. Vale salientar que em ambos os casos o transporte fluvial não ocorre no período da vazante, pois os rios ficam praticamente inacessíveis à navegação ou distantes das vias urbanas.

$\mathrm{Na}$ terceira tipologia, que denominamos de subinformais, ou seja, comerciantes que não apresentam qualquer tipo de documentação para a realização de atividades comerciais, assim como não dispõem de estabelecimento comercial fixo, com variação espacial nas práticas comerciais. Nesse segmento, destacam-se os ambulantes e os comerciantes-agricultores do grupo religioso israelita, os quais se inserem no mercado da cidade por meio de manobras similares, porém a origem das mercadorias têm características diferenciadas. Nesse sentido, destacam-se os comerciantes do grupo religioso israelita, que cultivam os produtos agrícolas comercializados na cidade. A origem dos produtos agrícolas é a partir do cultivo realizado às margens do rio Javari, no lado correspondente ao Peru, e chegam até a cidade através de embarcações próprias, em dias e horários específicos (segunda ou terça-feira, nas primeiras horas do dia). Porém, atualmente, com andamento de operações institucionais de fiscalização, a presença desses comerciantes varia no porto da cidade, às vezes chegam à noite ou durante a madrugada.

Os vendedores do grupo religioso israelita têm características peculiares. As mulheres vestem túnicas de uma só cor e cabelos cobertos por uma espécie de véu, e os homens com cabelos e barbas longas. Os agricultores que residem em solo peruano chegam a Benjamin Constant em períodos regulares, às segundas e terças-feiras ou em feriados festivos (páscoa, dia das mães, festas de final de ano). Em embarcações próprias, trazem produtos variados: frutas e verduras (banana, abacaxi, tomate, cebola, cheiro-verde, pimentão, farinha, folha para fazer o fãni), animais domésticos (porcos, galinhas, carneiros, bovinos), caças e outros animais capturados na floresta (tracajá, jabuti, macaco, porco, anta), bem como produtos e subprodutos da pecuária (leite de vaca ou de cabra, queijo e coalhada). Esses comerciantes não dispõem de estabelecimento comercial fixo, e vendem suas mercadorias logo que chegam, pois a população local (atravessadores, outros 
peruanos e a população em geral) os aguardam nas margens do rio; ou se posicionam nas proximidades do mercado municipal de Benjamin Constant.

Com base neste estudo, como sugere Milton Santos, pode-se inferir que os dois circuitos da economia se conectam a partir do fluxo das mercadorias oriundas de polos econômicos de empresas nacionais e multinacionais em escala regional (Manaus), nacional (Fortaleza, São Paulo, Minas Gerais), bem como em escala mundial (países da América do Sul e do Norte, Europa e Ásia). Entretanto, pudemos verificar a influência de redes urbanas, como sugere Corrêa (1989), em que cidades como Manaus e Iquitos exercem influência econômica a partir do fornecimento de mercadorias e serviços. E, ainda, arranjos econômicos em uma escala local, como salientado na produção agrícola comercializada pelo grupo religioso israelita que abastece a cidade de Benjamin Constant e outras cidades da região.

Essa dinâmica econômica produzida a partir da expansão do comércio realizado pelos peruanos, que atingem diferentes escalas geográficas e camadas sociais, produz e reproduz, além de um comércio peculiar, novas relações humanas com modos de vida que se traduzem num hibridismo do idioma, da gastronomia, da música, e da religião.

\section{NOVAS ESPACIALIDADES EM BENJAMIN CONSTANT}

A partir da análise de situações como as expressas no decorrer do texto, cabe a afirmativa de Martins (2012): “[...] nesse conflito, a fronteira é essencialmente o lugar da alteridade." Como o mesmo autor salienta: "é isso que faz dela uma realidade singular", na qual se verificam conflitos e tolerância com o outro, num espaço relativo que você também se insere como o outro simultaneamente, pois na faixa de fronteira estudada é frequente estar aqui e estar lá, ou estar lá e estar aqui.

As relações multiculturais e as multiterritorialidades inferidas por Haesbaert (2010) dinamizam-se num espaço poroso e, nesse sentido, podemos evidenciar os costumes alimentares e o idioma. Na cidade onde se realizou a pesquisa é comum crianças, jovens e adultos arriscarem um portunhol, pois o contato frequente com os peruanos (comerciantes, médicos, pedreiros, carpinteiros, borracheiros) permite e contribui para esse conhecimento, bem como na alimentação, de forma bem generalizada, a população local utiliza como ingrediente principal de suas receitas a banana, que, aliás, não é "pacovão", como denominada na capital do estado, sendo mais conhecida como "banana peruana". Também há o costume de consumir no café da manhã o "patacón" ou patacão (expressão adaptada pelos moradores), que são rodelas de bananas peruanas amassadas e fritas. No livro Amazonês - expressões e termos usados no Amazonas, de Sérgio Freire, encontrou- 
se a palavra "curite", que significa "Dindim. Usado na região do Alto Solimões", ou seja, sucos de fruta congelados em pequenos sacos plásticos. $\mathrm{O}$ consumo e o preparo de cerviche, lomo saltado e chicharron, comidas típicas peruanas que utilizam como ingredientes peixes e carnes tornaram-se comuns em Benjamin Constant. Também faz parte da cultura dos benjaminenses, além do preparo e consumo desses alimentos, a influência musical dos "vallenatos peruanos", ritmo dançante muito apreciado nos bares, boates e lares da cidade, além do consumo de bebidas como o Pisco, a cerveja Cusqueña, a Pilsen, assim como uma bebida que surgiu recentemente (2013-2014), denominada de Clima (um composto de bebida alcoólica misturada com refrigerante, vendida em garrafa $p e t t$ ).

Nas práticas cotidianas, raramente os peruanos e brasileiros compartilham as mesmas festas em Benjamin Constant. Aliás, é incomum encontrar peruanos em bares ou boates da cidade, pois nos parece que isso se configura como desperdício para esse segmento, que é muito comprometido com a rentabilidade e o êxito econômico. Todavia, em festividades relacionadas ao contexto peruano, uma parcela significativa de peruanos residentes em Benjamin Constant (do segmento informal e subinformal) se dirige à cidade vizinha, sendo as principais datas festivas a independência peruana e da municipalidade distrital de Islândia. Nesses momentos ocorrem programações esportivas que também envolvem atletas brasileiros de Benjamin Constant, bem como desfiles e queima de fogos. Nesses momentos festivos o gerador funciona no período noturno de forma constante, pois é comum a presença de moradores das cidades brasileiras da fronteira como Benjamim Constant, Tabatinga e Atalaia do Norte, que vão prestigiar os eventos, com se observa na Figura 14.

Figura 14 - Festa da municipalidade distrital em Islândia (Peru).

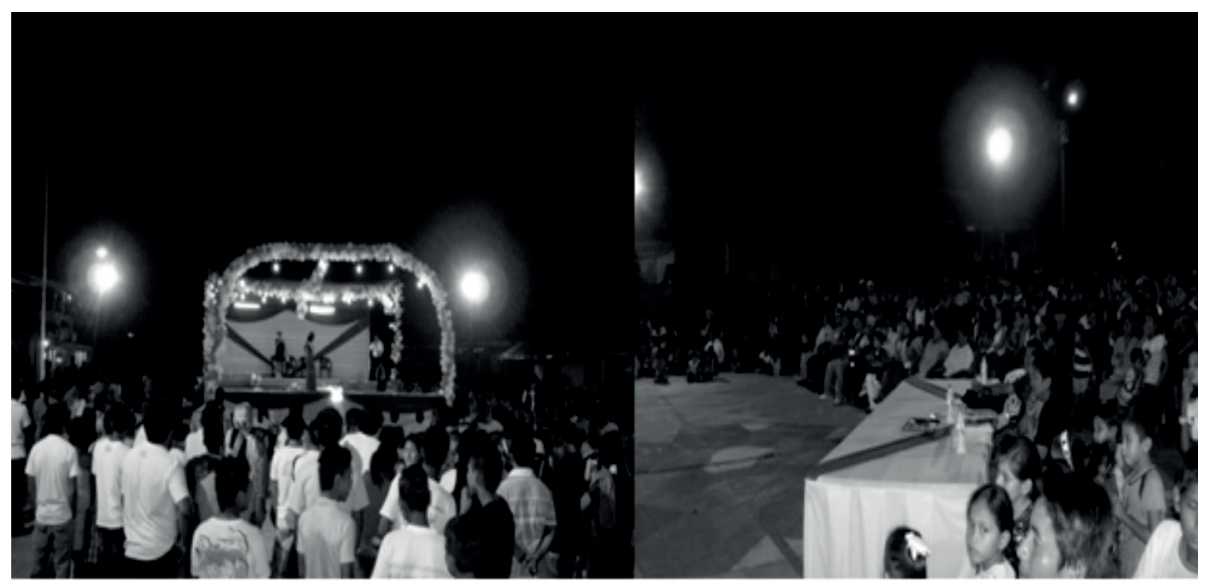

Fonte: Souza, pesquisa de campo, julho de 2012. 
As imagens se referem à festa da municipalidade distrital de Islândia, com a presença da população e autoridades locais, numa área equivalente a um ginásio esportivo a céu aberto (que em períodos de enchente fica submerso). No desfile das candidatas ao título de "garota yavar" foi recorrente no discurso destas a preocupação com a criação de departamentos de recepcionar turistas, o que caracteriza a preocupação da população em geral de recepcionar o turismo, como salientado anteriormente, visto que a cidade se prepara com projetos e construções de instituições para dinamizar a economia e aparentemente se tornar um polo regional.

Salienta-se, no âmbito das dinâmicas espaciais o movimento contínuo de ir e vir até a cidade de Islândia, pela preocupação de muitos peruanos residentes em Benjamin Constant com a educação dos filhos em Islândia. Talvez seja para assegurar o vínculo com a terra natal, mesmo porque pela falta de documentação ainda há dificuldade de se aceitar descendentes de peruanos nas escolas de Benjamin Constant. O certo é que diariamente uma embarcação faz o trajeto de Benjamin Constant levando aproximadamente 35 crianças para estudar em Islândia (Figura 15).

Figura 15 - Transporte de estudantes peruanos de Benjamin Constant para estudar em Islândia.

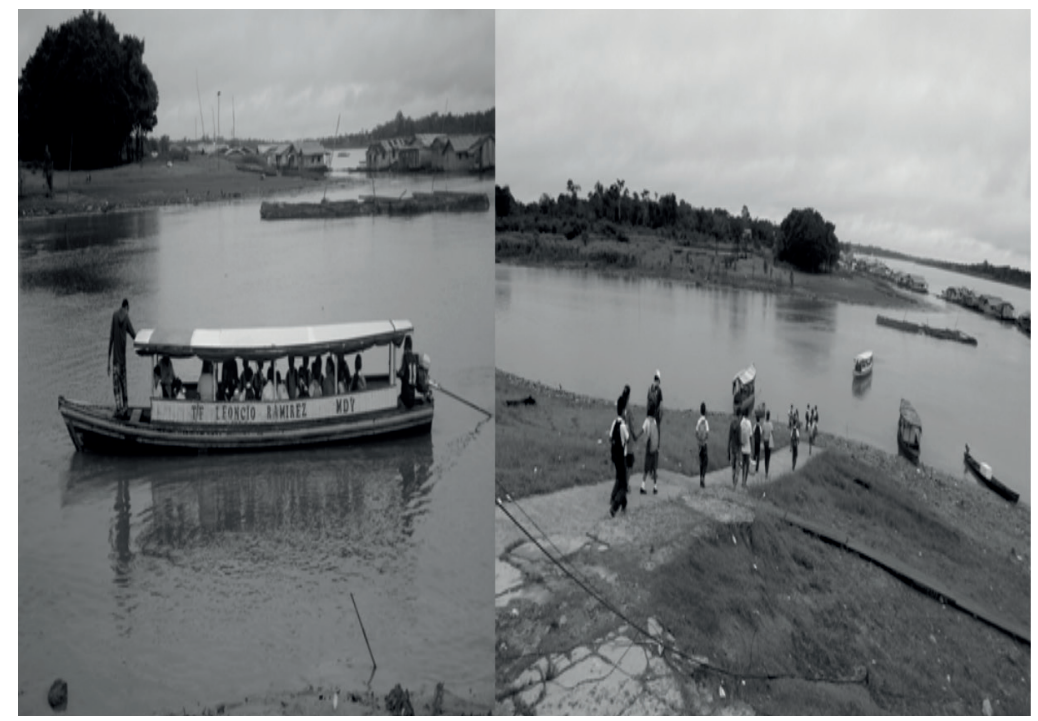

Fonte: SOUZA, pesquisa de campo, setembro de 2013.

Como se observa, as crianças a companhadas dos pais vão chegando até uma pequena embarcação que os aguarda à margem do rio, e saem aproximadamente 
às 6 h30 de Benjamin Constant para chegar antes das 7h00 em Islândia. Ressaltase que na época da pesquisa, em setembro de 2013, Benjamin Constant obedecia ao fuso horário da capital do estado, o que conferia uma diferença e confusão não somente neste aspecto, mas também em transações comercias, em horários de embarcações e voos. Este é um exemplo de medidas políticas que desconhecem as realidades das diferentes amazônias, principalmente nas cidades de fronteira. Atualmente, após muitos debates e discussões, os fusos horários voltaram à normalidade e estão compatíveis entre as cidades.

Contudo, uma das atividades que mais apresenta integração na fronteira são os jogos esportivos, como, por exemplo, os jogos denominados de "Três Fronteiras", que ocorrem anualmente no mês de fevereiro, em Atalaia do Norte, contando com a participação de atletas que representam os municípios que compõem o Alto Solimões, estendendo-se, como sugere o nome, à participação de atletas representantes de Letícia (Colômbia) e Islândia (Peru). Nesse contexto, percebe-se uma integração entre atletas de Benjamin Constant e Islândia, de forma que, em determinadas modalidades esportivas pouco praticadas em Islândia, inserem-se atletas de Benjamin Constant (Figura 16).

Figura 16 - Confraternização esportiva de atletas da tríplice fronteira em Atalaia do Norte.

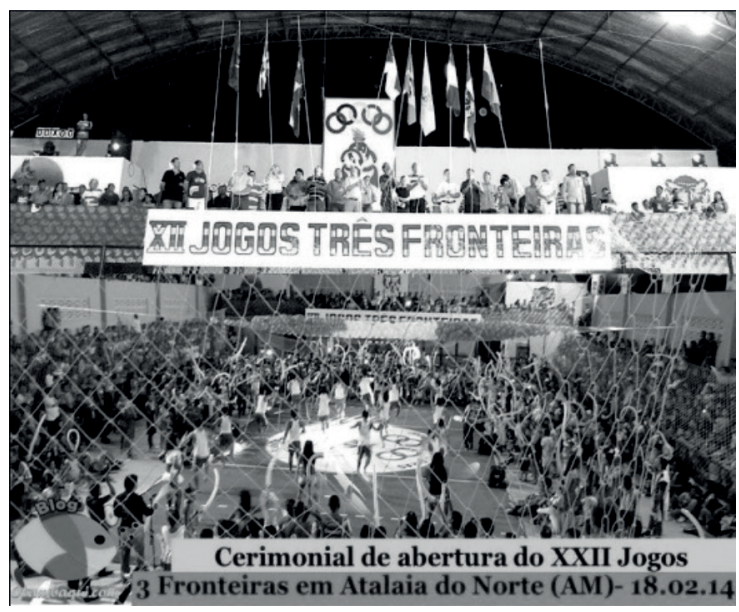

Fonte: http://www.otambaqui.com, em fevereiro de 2014.

O que a análise das atividades de segmentos de comerciantes peruanos na cidade de Benjamim Constant demonstra que há uma imbricação do espaço e da sociedade e a produção e reprodução das diferentes práticas que dão sentido à vida. Como acentua Ana Fani de Alessandri Carlos (2011), trata-se de avançar no 
entendimento de que as atividades de um modo geral não são apenas econômicas; são também sociais e culturais, e de que é "a atividade que produz a vida e com ela a realidade social realiza-se, necessariamente, num espaço-tempo apropriável para a ação" (CARLOS, 2011, p. 23).

Tal dimensão sintetiza o que se buscou mostrar com a caracterização das tipologias do comércio peruano na cidade de Benjamim Constant, em que, de uma atividade meramente econômica, articulam-se dimensões bem mais amplas, que vão moldando novas espacialidades para a cidade. Claro que esse processo se estabelece na situação da cidade em área de fronteira, que incorpora as dimensões espaço-tempo em que foram se produzindo aquele território.

\section{CONSIDERAÇÕES FINAIS}

As cidades amazônicas são lugares onde pulsam culturas e modos de vida diferenciados. Apesar de uma cidade de fronteira carregar em seu bojo temporal, histórico e espacial geográfico o estigma de uma região que obedece a interesses distantes, incorporado a agenda nacional como uma área de "segurança nacional" e como cidade de fronteira, ou no imaginário difundido pela mídia como rotas do tráfico de drogas, estas cidades se transformam no tempo e no espaço e produzem especificidades sociais, econômicas e culturais que as colocam para além do discursos elaborados sobre elas.

Ao se estudar mais profundamente o comércio local, verificou-se que em Benjamin Constant 63\% dos estabelecimentos distribuídos nas principais vias da área central são de proprietários peruanos, e já se ampliando para os demais bairros. Portanto, trata-se de uma questão importante, e que influencia a espacialidade naquela região. Porém, o predomínio deste comércio não está somente no fato de trabalharem com mercadorias ditas "ilegais", sem pagamento de impostos ou tarifas fiscais para entrar no Brasil, mas também pela distância geográfica dos polos industriais nacionais, pelo perfil do trabalhador migrante, pela diversidade e sortimento de mercadorias, além dos preços mais acessíveis.

Esses aspectos são contributos pontuais que decorrem de fatores mais estruturais, como a ausência ou inadequação de políticas públicas que possibilitem o acesso por parte das populações de Benjamim Constant, como em outros lugares da Amazônia, a produtos nacionais a preços acessíveis, o que é justificado pela distância geográfica dos principais centros produtores. Um bom exemplo disso é a gasolina importada de forma ilegal que é vendida em pequenos comércios em garrafas pet de 2 litros, a preços bem menores do que os praticados no comércio formal. 
Cabe salientar também as políticas ambientais que se limitam a atuar no campo da conservação dos recursos naturais, sem levar em consideração os impactos sociais que essas políticas provocam sobre as populações locais. De nenhuma forma cogita-se ir contra as medidas ambientais, como se posicionam oportunamente vários segmentos da sociedade local, visando encobrir a falta de preparo para fazer frente às questões postas como novos desafios contemporâneos. Porém, deve-se reconhecer que não são viabilizadas políticas e alternativas de desenvolvimento sustentável às populações locais.

É possível inferir pelas observações de campo e análises sobre Benjamin Constant, uma cidade amazônica contextualizada como periférica nacional, em que as dificuldades de acesso aos bens e serviços urbanos existentes não podem ser atribuídas somente à distância geográfica de Manaus, em que as embarcações que efetuam o transporte de cargas e passageiros na região levam de cinco a oito dias para a travessia Manaus-Benjamin Constant, dependendo da sazonalidade do rio, mais do que isso, decorre da falta ou inadequação das políticas públicas do Estado Brasileiro voltadas para compreender uma região como a Amazônia, e neste caso específico, considerando a área da tríplice fronteira como estratégica do ponto de vista geopolítico, sendo a população local a principal riqueza. $\mathrm{Na}$ prática, entretando, percebe-se que esta relação de distanciamento do centro industrial nacional, provoca efeitos marcantes em termos econômicos, na qual produtos sofrem uma elevação absurda dos preços. Nesse contexto, as mercadorias oferecidas pelos comerciantes peruanos é fator de equilíbrio na economia local, seja em qual for o segmento - formal, informal ou subinformal. Ou seja, com as alternativas de acesso a mercadorias de outros mercados que não os de Manaus, ou nacionais, os comerciantes peruanos estabelecem preços mais acessíveis e ofertam uma variedade de produtos que atendem principalmente a população de baixo poder aquisitivo, ou seja, a maior parte da população de Benjamin Constant. Isso explica a aceitação, apesar das reticências e do preconceito porque são de grande utilidade para a cidade.

Outra característica de destaque está na origem dos produtos. Pode-se afirmar que priorizam mercadorias tipicamente da área de tríplice fronteira, pois os comerciantes peruanos (tipologia informal e subinformal) ofertam produtos do Peru, Colômbia e Brasil, dependendo da facilidade na aquisição tanto em função dos preços quanto da logística de transporte. Neste sentido, salienta-se que os comerciantes de maior destaque nesse mercado trabalham com produtos oriundos de diversas partes do Brasil, como, por exemplo, os comerciantes do ramo do vestuário adquirem suas mercadorias em cidades como São Paulo, Fortaleza e Goiânia. 
Nesse contexto, Benjamin Constant é uma cidade que deve ser vista em diferentes dimensões, não somente como área de segurança nacional, zona de litígio, de ilegalidade e tráfico de drogas, como é divulgada nos meios de comunicação em massa, mas também uma cidade que se adapta às condições básicas de sobrevivência, sendo uma parcela significativa suprida pela contribuição do comércio peruano. A partir dessa vivência e convivência na fronteira, percebe-se o aspecto da tolerância ao outro, da alteridade de pensar e absorver modos de vida e costumes que se ressiginificam na linguagem, na música, no vestuário e na culinária.

Analisar uma cidade da tríplice fronteira exige reflexões para produzir conhecimentos que não tomem como ponto de partida somente as definições legais, visões fragmentadas, e do senso comum, mas também não os refutar, porque fazem parte do processo, mas é preciso ir além, e tentar reconhecer espaços e práticas em que pulsam modos de vida diferenciados, em uma dinâmica esfacelada que se metamorfoseia no tempo e no espaço, na qual se evidenciam tanto as nuances da modernização como a rotina cotidiana de uma vida ribeirinha amazônica.

\section{REFERÊNCIAS}

CARLOS, A. F. A. A condição espacial. São Paulo: Editora Contexto, 2011.

CORRÊA, R. L. A rede urbana. São Paulo: Ática, 1989.

HAESBAERT DA COSTA, R. O mito da desterritorialização: do "fim dos territórios" à multiterritorialidade. 5. ed. Rio de Janeiro: Bertrand Brasil, 2010.

IBGE - Censo Demografico. 2010

MAGNANI, J. G. C. Da periferia ao centro: trajetórias de pesquisa em Antropologia Urbana. São Paulo: Editora Terceiro Nome, 2012.

MARTINS, J. de S.. Fronteira: a degradação do Outro nos confins do humano. 2. ed.. São Paulo: Contexto, 2012.

SCHOR, T.; OLIVEIRA, J. A. de. Reflexões metodológicas sobre o estudo da rede urbana no Amazonas e perspectivas para a análise das cidades na Amazônia Brasileira. ACTA Geográfica. Ed. Esp. Cidades na Amazônia Brasileira, 2011.

SANTOS, M. O espaço dividido: os dois circuitos da economia urbana dos países subdesenvolvidos. Tradução Myrna T. Rego Viana. $2^{\mathrm{a}}$ ed. São Paulo: Editora da Universidade de São Paulo, 2004.

SILVA, S. A. da (org.). Migrações na pan-Amazônia: fluxos, fronteiras e processos socioculturais. São Paulo: Hucitec; Manaus: FAPEAM, 2012.NOGUEIRA, R. J. B. As redes geográficas na fronteira da Amazônia. Acta Geográfica, v. II, n. 3, jan./jun., 2008. 
SCHOR, T.; OLIVEIRA, J. A. de. Reflexões metodológicas sobre o estudo da rede urbana no Amazonas e perspectivas para a análise das cidades na Amazônia Brasileira. Acta Geográfica, v. V, [Edição Especial Cidades na Amazônia Brasileira], 2011.

SANTOS, M. O espaço dividido: os dois circuitos da economia urbana dos países subdesenvolvidos. Tradução Myrna T. Rego Viana. 2. ed. São Paulo: EDUSP, 2004.

SILVA, S. A. da (Org.). Migrações na pan-Amazônia: fluxos, fronteiras e processos socioculturais. São Paulo: Hucitec; Manaus: FAPEAM, 2012. 